\title{
Supplementary Material to: Investigating soil moisture-climate interactions with prescribed soil moisture experiments: an assessment with the Community Earth System Model (version 1.2)
}

Mathias Hauser ${ }^{1}$, René Orth ${ }^{1}$, and Sonia I. Seneviratne ${ }^{1}$

${ }^{1}$ Institute for Atmospheric and Climate Science, ETH Zurich, Zurich, Switzerland

Correspondence to: Mathias Hauser (mathias.hauser@env.ethz.ch)

This document provides Supplementary Material for 'Investigating soil moisture-climate interactions with prescribed soil moisture experiments: an assessment with the Community Earth System Model (version 1.2)'. It includes Figure S1 to Figure S9.

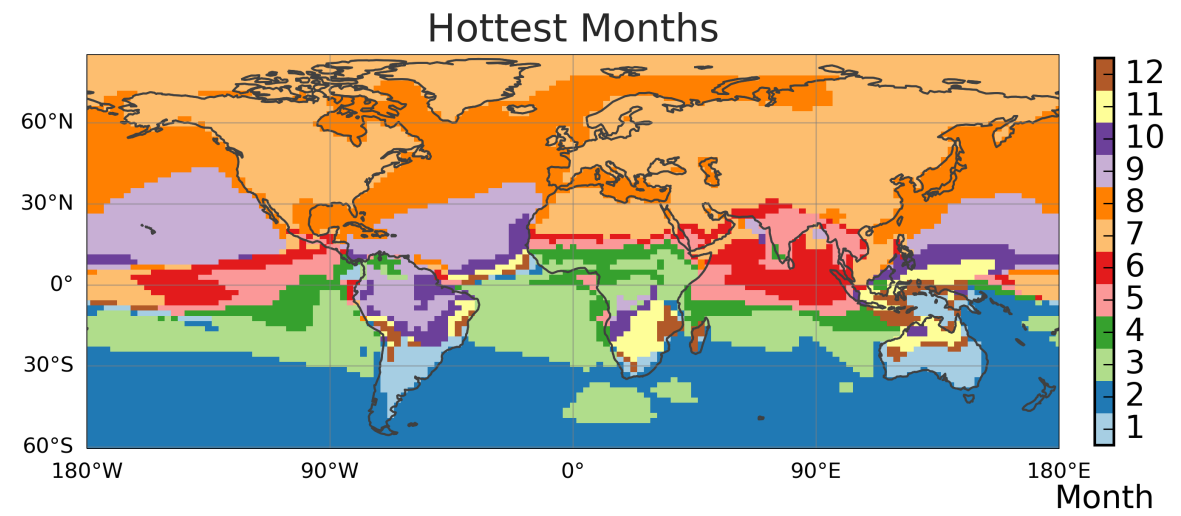

Figure S1. Central month of the three hottest consecutive months during 1971 to 2000 in REF, used for Figure 1, (b), (c), (e), and (f) and Figure S2. 


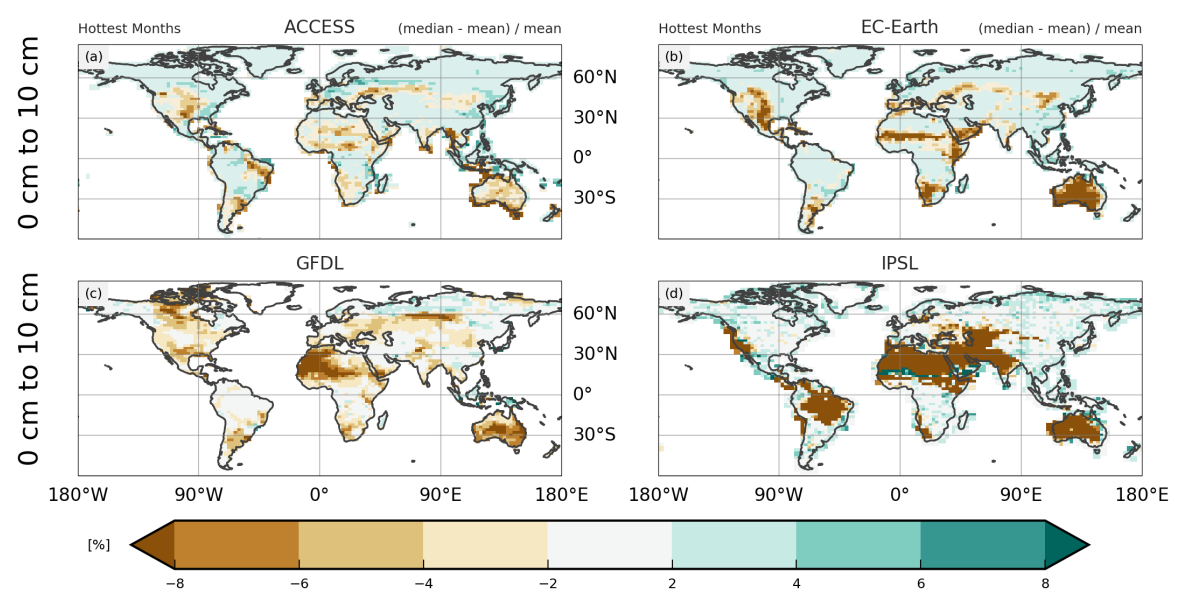

Figure S2. Relative difference in the soil moisture climatology between median and mean for the hottest months of the year for the topmost $10 \mathrm{~cm}$ of the soil (as Figure 2 (b)) for four models participating in GLACE-CMIP5: (a) ACCESS, (b) EC-Earth (c) GFDL and (d) IPSL. The two missing models are ECHAM, which did not provide the necessary data and CESM itself. For IPSL, monthly data is used. For simplicity the same three consecutive hottest months from CESM are used (see Figure S1). For abbreviations and references of the models please see Seneviratne et al. (2013) and Lorenz et al. (2016).
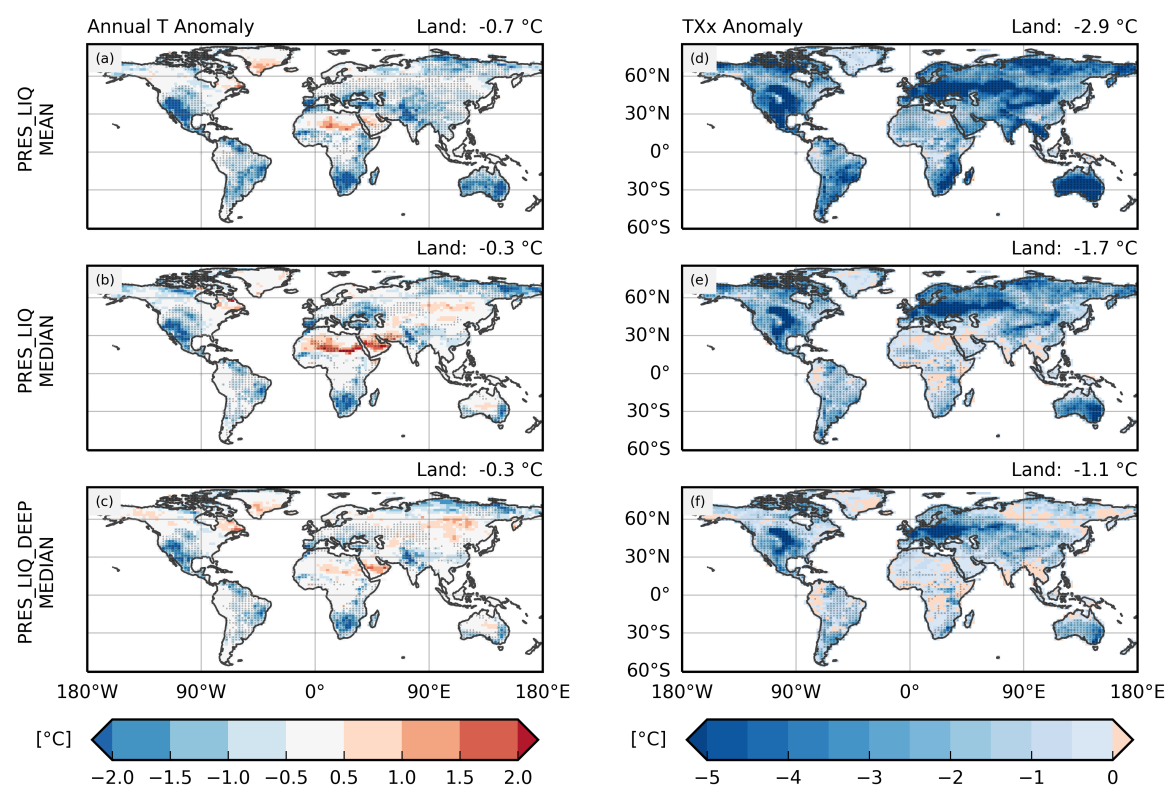

Figure S3. As Figure 3 but for 2070 to 2099. 

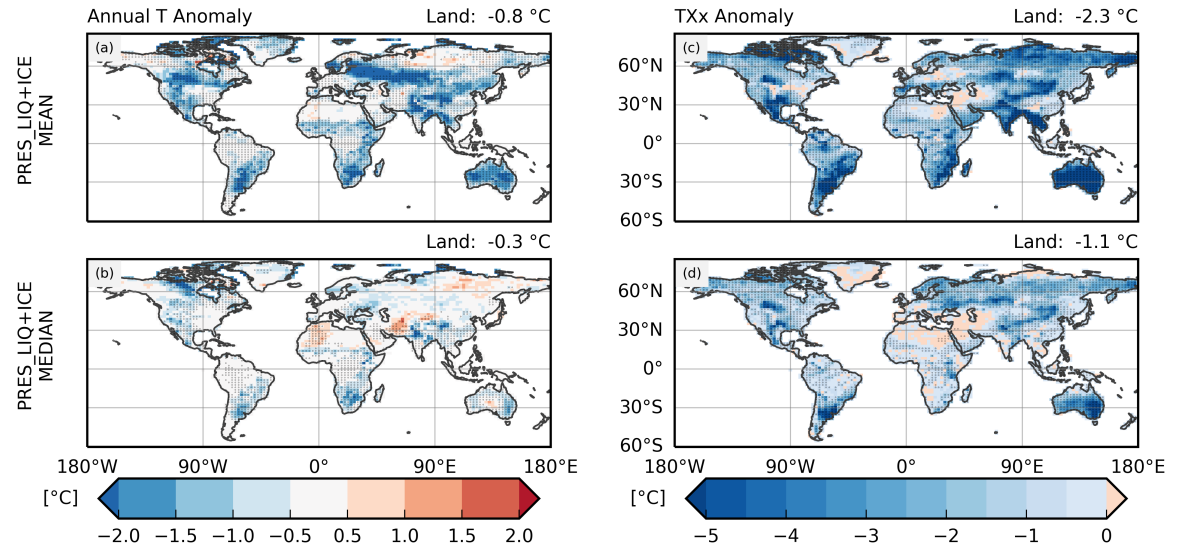

Figure S4. As Figure 3 but for the simulations which prescribe ICE, PRES_LIQ+ICE_MEAN and PRES_LIQ+ICE_MEDIAN.
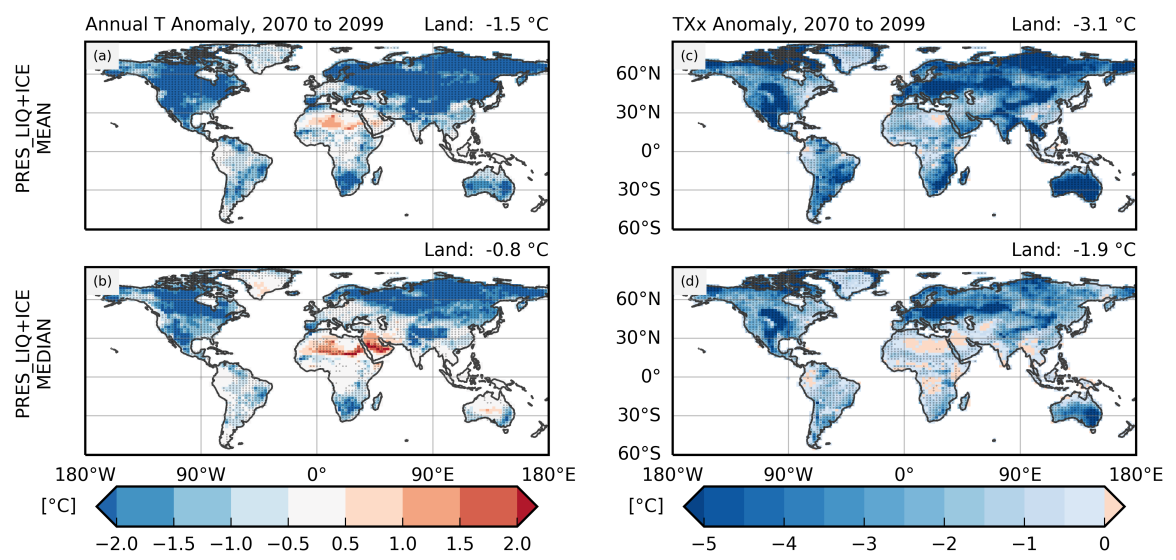

Figure S5. As Figure S4 but for the end of the 21st century. 

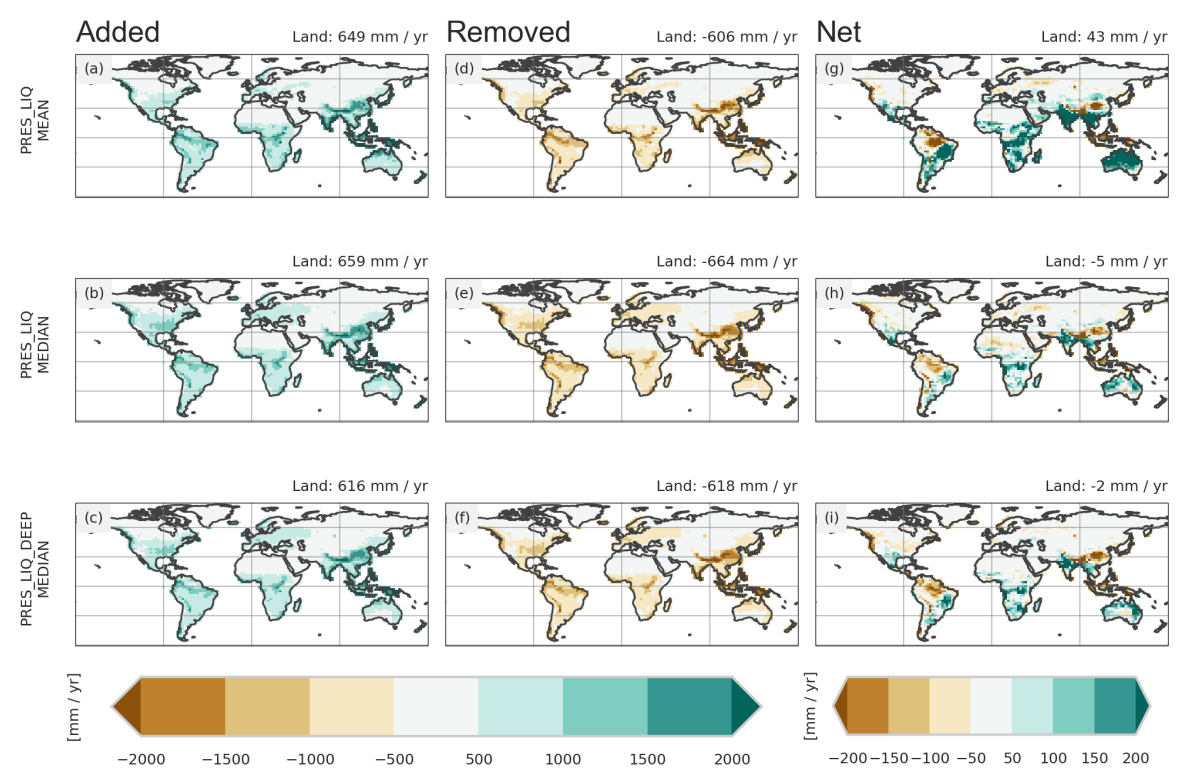

Figure S6. Mean annual soil moisture perturbation for 2070 to 2100. (a) to (c) added soil moisture, (d) to (f) removed soil moisture and (g) to (i) net soil moisture perturbation. Subfigures (g) to (i) are equal to Figure 4 (a) to (c).
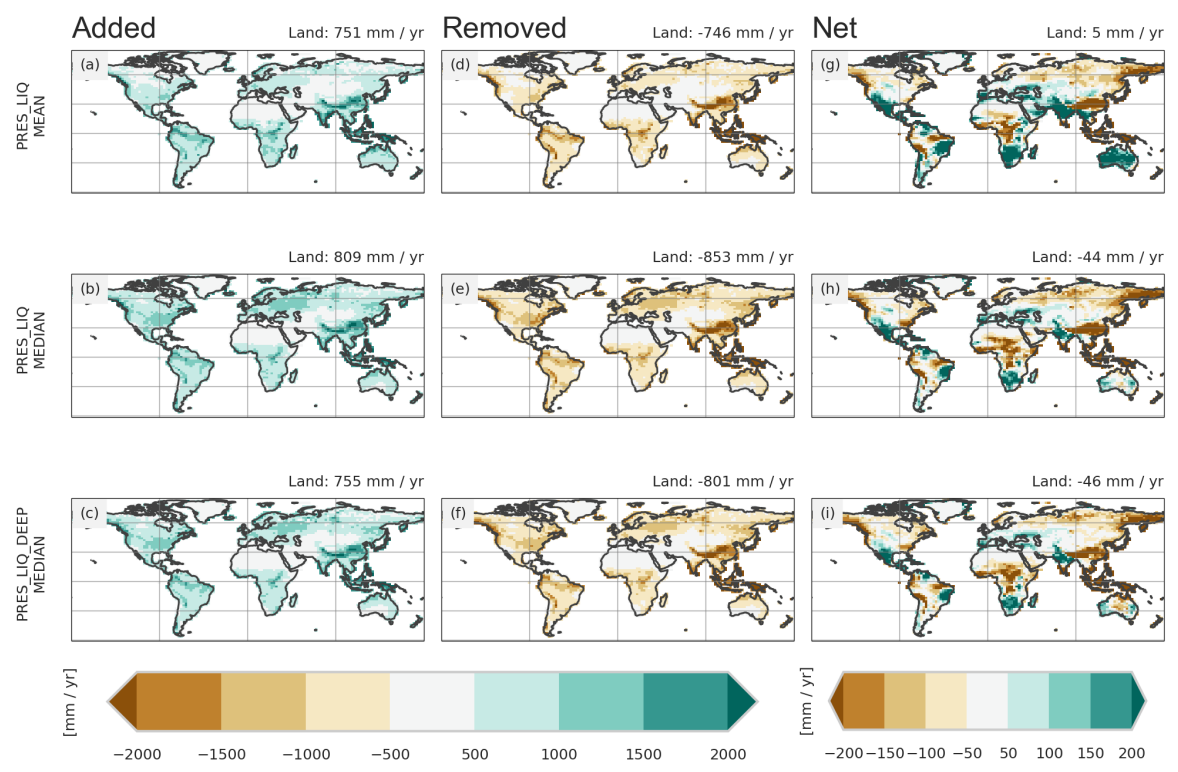

Figure S7. As Figure S6 but for the end of the 21st century. 


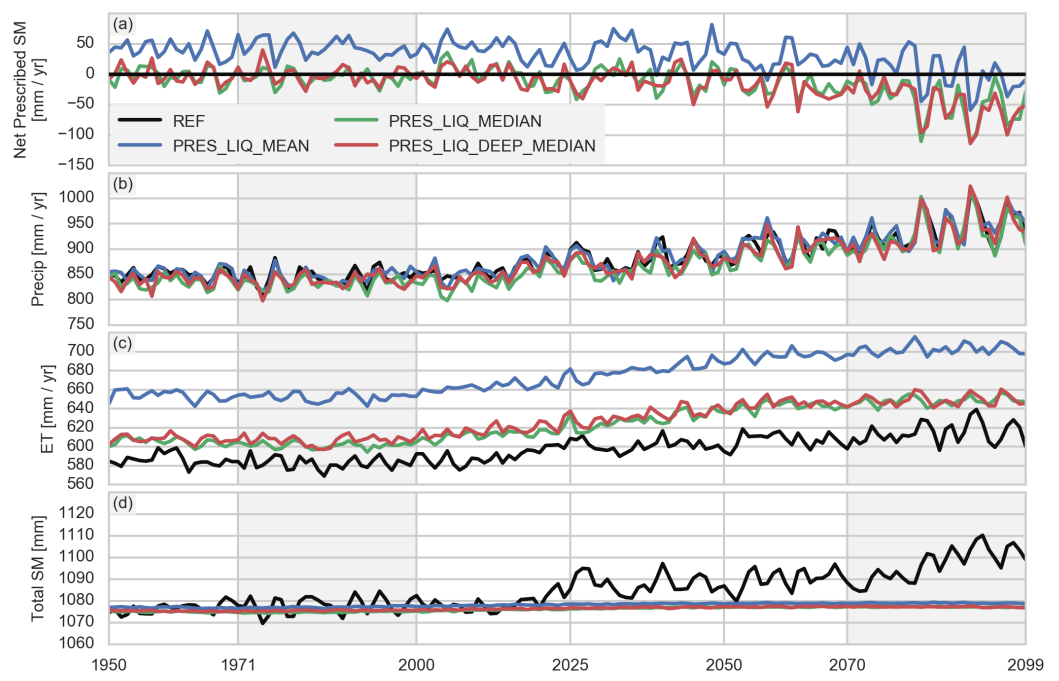

Figure S8. Time series of global-land, annual-mean (a) net prescribed soil moisture, (b) precipitation, (c) evapotranspiration (ET) and, (d) total soil moisture content. Total soil moisture in the simulations with prescribed soil moisture is not a totally straight line because ICE is still computed interactively. The light gray background shows the two time periods used for the climatology.
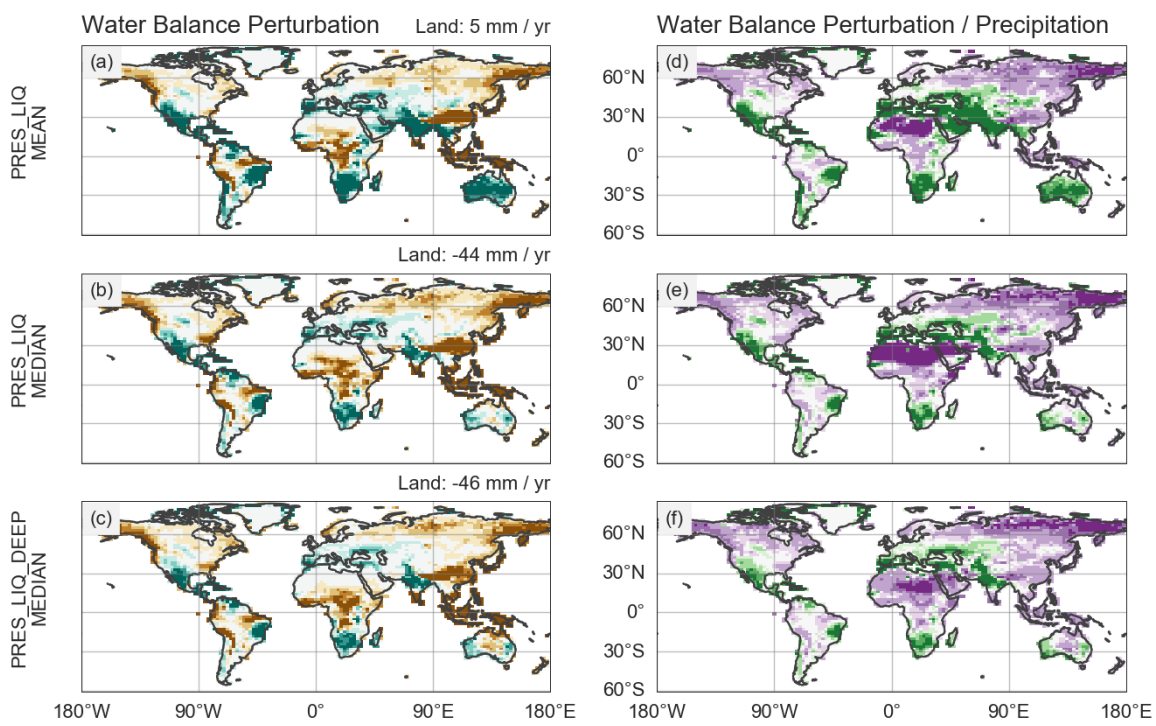

$[\mathrm{mm} / \mathrm{yr}]$

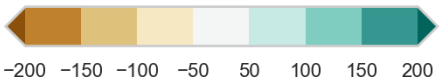

[\%]

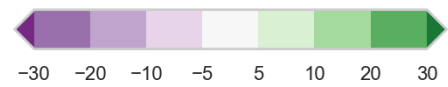

Figure S9. As Figure 4 but for 2070 to 2099. Subfigures (a) to (c) are equal to Figure S7 (g) to (i). 


\section{References}

Lorenz, R., Argueeso, D., Donat, M. G., Pitman, A. J., van den Hurk, B., Berg, A., Lawrence, D. M., Cheruy, F., Ducharne, A., Hagemann, S., Meier, A., Milly, P. C. D., and Seneviratne, S. I.: Influence of land-atmosphere feedbacks on temperature and precipitation extremes in the GLACE-CMIP5 ensemble, Journal of Geopyhsical Research-Atmospheres, 121, 607-623, doi:10.1002/2015JD024053, 2016.

5 Seneviratne, S. I., Wilhelm, M., Stanelle, T., van den Hurk, B., Hagemann, S., Berg, A., Cheruy, F., Higgins, M. E., Meier, A., Brovkin, V., Claussen, M., Ducharne, A., Dufresne, J.-L., Findell, K. L., Ghattas, J., Lawrence, D. M., Malyshev, S., Rummukainen, M., and Smith, B.: Impact of soil moisture-climate feedbacks on CMIP5 projections: First results from the GLACE-CMIP5 experiment, Geophysical Research Letters, 40, 5212-5217, doi:10.1002/grl.50956, 2013. 